\title{
Análise do processo tradutório de estudantes de tradução e tradutores profissionais no par linguístico Chinês mandarim $=>$ Português europeu $^{1}$ Analysis of the translation process of translation students and professional translators in the language pair Mandarin Chinese => European Portuguese
}

Márcia Schmaltz (in memoriam)*

Norma Fonseca ${ }^{* * *}$

Cecília Frugoli ${ }^{* * *}$

Fabio Alves ${ }^{* * * * *}$

\begin{tabular}{ll}
\hline RESUMO: Baseando-se em métodos & ABSTRACT: Drawing on methods \\
usados na pesquisa processual em & developed for translation process \\
tradução, este estudo objetiva analisar o & research, this study aims to analyze the \\
processo tradutório de nove tradutores & translation process of nine professional \\
profissionais e oito estudantes sem & translators and eight students without \\
experiência profissional em tradução. & professional experience in translation. \\
Eles executaram uma tarefa de tradução & They performed a translation task of a \\
de um texto jornalístico no par linguístico & news text in the language pair Chinese \\
chinês mandarim $=>$ português europeu. & Mandarin $=>$ European Portuguese. Prior \\
\hline
\end{tabular}

${ }^{1}$ Neste artigo, homenageamos a profa. Dra Márcia Schmaltz (1973-2018) apresentando os resultados
da última pesquisa coorientada por ela quando cursava o pós-doutorado no Programa de Pós-Graduação
em Estudos Linguísticos (PosLin), na UFMG. Ademais, fornecemos, no Anexo B, um texto-alvo em
Português europeu traduzido pela pesquisadora, a partir do texto-fonte em Chinês mandarim utilizado
para o desenvolvimento da pesquisa aqui relatada, proporcionando ao leitor deste artigo uma amostra
de como a tradutora divulgava a China aos falantes de português. Obras traduzidas por Márcia Schmaltz
incluem 50 Fábulas da China Fabulosa, publicada em 2007, Viver, de Yu Hua, em 2008, Contos
Sobrenaturais Chineses, em 2010 , e Fábulas Chinesas, em 2012, sendo algumas delas em parceria com
o tradutor e escritor Sérgio Capparelli.
* Doutora em Linguística pela Universidade de Macau. Pós-doutorado na Universidade
Federal de Minas Gerais (UFMG). 0000-0002-8315-9695.
${ }^{* *}$ Doutora em Estudos Linguísticos pela Universidade Federal de Minas Gerais (UFMG). Docente no
Centro Federal de Educação Tecnológica de Minas Gerais (CEFET-MG). ORCID: 0000-0002-8315-
9695. normafonseca@gaínail.com
${ }^{* * * *}$ Bacharel em Linguística pela Universidade Federal de Minas Gerais (UFMG). ORCID: 0000-0002-
5235-5781. ceciliagofrugoli@gmail.com.
${ }_{* * * *}$ Doutor em Linguística Aplicada pela Ruhr Universität Bochum. Professor Titular (PosLin), da
Universidade Federal de Minas Gerais (UFMG). ORCID: 0000-0003-1089-4864. fabio-alves@ufmg.br 
Antes de executarem a tarefa utilizando o programa Translog (JAKOBSEN; SCHOU, 1999), os participantes responderam a um questionário de perfil. Após finalizarem a tarefa de tradução, os participantes relataram livremente sobre seu desempenho no processo tradutório por meio de protocolos verbais retrospectivos livres. Os resultados obtidos confirmaram achados de estudos anteriores indicando que tradutores profissionais despendem menos tempo na execução de tarefas de tradução que estudantes (JAKOBSEN, 2002; BUCHWEITZ; ALVES, 2006; PAVLOVIĆ; JENSEN, 2009; JAKOBSEN; JENSEN, 2008). Contudo, o estudo não confirmou que tradutores profissionais despendam mais tempo na fase de revisão que os estudantes (JAKOBSEN, 2002; BUCHWEITZ; ALVES, 2006). Os resultados mostraram também que os estudantes de tradução apresentaram maior velocidade de tradução, traduzindo mais palavras por minuto que os tradutores profissionais, o que não confirma os achados de Jakobsen (2003). Por fim, há uma indicação de que os tradutores profissionais têm maior nível de metarreflexão que os estudantes de tradução (ALVES, 2005).

PALAVRAS-CHAVE: Fases do processo tradutório. Tempo total de execução de tarefa. Protocolos verbais retrospectivos livres. Velocidade de tradução. Metarreflexão. to task execution using the Translog software (JAKOBSEN; SCHOU, 1999), participants answered a profile questionnaire. Upon translation task execution, participants reported on their performance through free retrospective verbal protocols. Results confirmed findings of previous studies evidencing professional translators take a shorter time to perform translation tasks than students (JAKOBSEN, 2002; BUCHWEITZ; ALVES, 2006; PAVLOVIĆ; JENSEN, 2009; JAKOBSEN; JENSEN, 2008). However, the study did not show that professional translators have a longer revision phase than translation students (JAKOBSEN, 2002; BUCHWEITZ; ALVES, 2006). Results also showed that students worked at a higher translation speed, translating more words per minute than students, thus not confirming Jakobsen's (2003) findings. Finally, professional translators were found to show a higher level of metareflection than translation students (ALVES, 2005).

KEYWORDS: Phases of Translation Process. Total Task Execution Time. Free retrospective verbal protocols. Translation Speed. Metareflection.

\section{Introdução}

Conforme afirma Hurtado Albir (2001, p. 375), a tradução é uma “atividade cognitiva complexa". Portanto, estudar o processo tradutório é fundamental para se 
entender o que diferencia estudantes de tradução de tradutores profissionais, principalmente em pares linguísticos pouco explorados nos estudos processuais da tradução, como é o caso do chinês mandarim => português europeu.

Para preencher essa lacuna, um estudo foi realizado no Laboratório Experimental de Tradução (LETRA) da Universidade Federal de Minas Gerais (UFMG), visando investigar o processo tradutório de quinze participantes, durante a execução de uma tarefa de tradução de um texto intitulado "O chá verde" no par linguístico mencionado. Os dados analisados neste estudo foram coletados no Laboratório de Computação da Universidade de Macau, em um trabalho de parceria com o LETRA, sendo a tarefa realizada pelos participantes sem pressão de tempo e com possibilidade de consulta à internet.

Para dar consecução ao objetivo geral do estudo, os dados coletados foram analisados com vistas a examinar:

1) o tempo total de execução da tarefa dos tradutores profissionais e dos estudantes de tradução;

2) a distribuição do tempo de execução da tarefa de tradução nas fases do processo tradutório;

3) a velocidade de tradução dos tradutores profissionais e dos estudantes de tradução; e

4) o nível de metarreflexão dos tradutores profissionais e dos estudantes de tradução.

Por meio dessa análise, este estudo busca responder às seguintes perguntas de pesquisa:

1) Qual é a influência da experiência em tradução no tempo total de execução de uma tarefa de tradução realizada por tradutores profissionais e estudantes de tradução no par linguístico chinês mandarim => português europeu? 
2) Qual é o impacto dessa experiência na distribuição desse tempo total nas fases de orientação, redação e revisão do processo tradutório?

3) Como a experiência em tradução influencia a velocidade de tradução de tradutores profissionais e estudantes de tradução?

4) Qual é a influência da experiência em tradução no nível de metarreflexão?

Para responder a essas perguntas, quatro hipóteses são formuladas:

1) Os tradutores profissionais executam tarefas de tradução mais rapidamente que os estudantes de tradução (JAKOBSEN, 2002; JAKOBSEN; JENSEN, 2008).

2) Os tradutores profissionais despendem mais tempo na fase de revisão que os estudantes de tradução (JAKOBSEN, 2002; BUCHWEITZ; ALVES, 2006).

3) Os tradutores profissionais apresentam maior velocidade de tradução que os estudantes de tradução (JAKOBSEN, 2002).

4) Os tradutores profissionais possuem maior nível de metarreflexão que os estudantes de tradução (ALVES, 2005).

Para descrever a pesquisa realizada, este artigo é composto por quatro seções, além desta Introdução. A segunda seção, Pressupostos teóricos, apresenta e discute estudos que embasaram o presente trabalho. Em seguida, a seção Metodologia detalha o método de coleta e de análise dos dados. Na quarta seção, os resultados do estudo são analisados e discutidos, baseando-se nos estudos e conceitos apresentados na segunda seção. Por fim, nas Considerações finais, são apresentadas conclusões e sugestões de pesquisas futuras.

\section{Pressupostos teóricos}

Os estudos processuais da tradução têm como principal interesse investigar a cognição no âmbito da execução de uma tarefa de tradução. Conforme salientam Hurtado Albir e Alves (2009, p. 68), “as pesquisas empíricas experimentais em tradução escrita começaram no início dos anos 80, com uma linha de pesquisa baseada 
principalmente em (...) TAPs", sendo essa fase considerada a primeira fase dos estudos processuais da tradução. A segunda fase, como acrescentam os autores, "deu ênfase a perspectivas multimetodológicas, especificamente a triangulação" (HURTADO ALBIR; ALVES, 2009, p. 70), tendo como marco metodológico a criação do Translog, um programa criado por Jakobsen e Schou (1999) para registrar o processo tradutório. Na terceira fase dos estudos processuais, de acordo com Hurtado Albir e Alves (2009), houve a inclusão de técnicas como o rastreamento ocular, que permitem, por exemplo, o mapeamento de movimentos oculares, como sacadas e fixações, durante a execução de uma tarefa de tradução. Os autores ainda salientam o desenvolvimento recente de outras linhas de pesquisa que exploram a ativação do cérebro, como a eletroencefalografia (EEG) e a neuroimagiologia (fMRI).

Principal técnica adotada na primeira fase dos estudos processuais da tradução, os protocolos verbais têm sido utilizados desde meados da década de 1980. Nos estudos iniciais em que essa técnica foi utilizada, há referência aos TAPs (Think-aloud protocols), os chamados protocolos verbais concomitantes. Atualmente, são utilizados também os protocolos verbais retrospectivos. Um protocolo verbal é concomitante se o sujeito verbaliza seus pensamentos e ações enquanto realiza uma tarefa, e é retrospectivo se o sujeito verbaliza pensamentos e ações após a conclusão da tarefa. Independentemente do tipo de protocolo, Gonçalves (2001, p. 14) afirma que o “objetivo dessa metodologia é tentar inferir alguns mecanismos ou processos cognitivos através das respectivas verbalizações".

No entanto, há críticas com relação à validade e à confiabilidade desses protocolos. Como aponta Gonçalves (2001, p. 20), o principal problema dessa técnica é que esta se apoia na “subjetividade dos participantes”. Apesar disso, Gonçalves (2001, p. 23) mostra-se favorável ao uso dos protocolos ao afirmar que os "protocolos verbais podem trazer grande contribuição para o estudo de determinados processos cognitivos". A sobrecarga cognitiva causada pelos TAPs (JAKOBSEN, 2003), conforme 
estudo citado a seguir, tem desestimulado o uso específico dos protocolos concomitantes em pesquisas processuais em tradução. Por esse motivo, muitos pesquisadores têm optado por utilizar protocolos verbais retrospectivos em pesquisas experimentais para análises mais amplas, porque esses protocolos, em conjunto com a função Replay do programa Translog, “(...) permitem a captura de dados inferenciais indiretos sobre a utilização de apoio interno" (ALVES, 2005, p. 113).

Jakobsen (2003) analisa a influência dos TAPs na velocidade de tradução, na revisão e na segmentação, partindo dos resultados de um experimento em que dois grupos de participantes (quatro estudantes de tradução e cinco tradutores profissionais) traduziram dois textos do inglês para o dinamarquês e dois textos do dinamarquês para o inglês, ou seja, fizeram duas tarefas de tradução L2=>L1 e duas tarefas de tradução L1=>L2. Cada grupo de participantes traduziu uma tarefa com TAP e outra sem TAP em cada direção da tradução (L1=>L2 e L2=>L1). Para o presente estudo, destacam-se os resultados do estudo de Jakobsen (2003) relativos à duração das tarefas realizadas sem TAP e na direção L1=>L2 por cada grupo de participantes. Desse modo, descrevem-se os resultados referentes ao processo tradutório do texto 1, que continha 367 caracteres com espaço, traduzido pelos tradutores profissionais, e do texto 2, que continha 522 caracteres com espaço, traduzido pelos estudantes de tradução, que atendem aos requisitos de direção do presente estudo (L1=>L2) e de ausência de TAP.

Segundo Jakobsen (2003), a duração média da tradução do texto 1 executada pelos tradutores profissionais foi de 11 minutos e 4 segundos, ou seja, 664 segundos, enquanto a duração média da tradução do texto 2 realizada por estudantes de tradução foi de 16 minutos e 14 segundos, ou seja, 974 segundos. Jakobsen (2003) observa que os tradutores profissionais concluíram a tarefa de tradução do texto 1 em menos tempo que os estudantes traduziram o texto 2. Entretanto, esses resultados devem ser tomados com cautela, uma vez que, conforme informa Jakobsen (2003), o texto-fonte 
traduzido pelos tradutores profissionais tinha uma extensão menor que o texto-fonte traduzido pelos estudantes de tradução.

Jakobsen (2002) utiliza dados de teclado e mouse registrados pelo programa Translog para identificar três diferentes fases do processo tradutório: orientação, redação e revisão. A fase inicial de orientação é "o intervalo de tempo entre o surgimento do texto-fonte na tela e o pressionamento da primeira tecla de produção textual" $^{\prime 2}$ (JAKOBSEN, 2002, p. 192). Nessa fase, aparecem movimentos de mouse e teclas de navegação que indicam a movimentação feita pelo texto bem como seu redimensionamento. Apesar de não haver produção textual nessa fase, os dados dela evidenciam quanto tempo o participante olhou para o texto-fonte e se efetivamente o leu para compreendê-lo. Jakobsen (2002) aponta ainda que a pausa inicial dessa fase é geralmente maior que as encontradas na fase de redação, a segunda fase, o que indica o processamento cognitivo do texto-fonte.

A fase de redação, por sua vez, "ocorre da digitação da primeira letra do textoalvo até a digitação do último sinal de pontuação"3 (JAKOBSEN, 2002, p. 192). Nessa fase, pode ocorrer o acionamento de teclas de produção textual e de exclusão, como backspace e delete, bem como movimentos de mouse, teclas de edição e de navegação. O autor caracteriza essa fase como irregular, uma vez que “[m]udanças são feitas, erros de digitação são corrigidos, o texto produzido é excluído e substituído por um novo texto" ${ }^{4}$ (JAKOBSEN, 2002, p. 193). O autor afirma ainda que a fase de redação inclui também o que ele chama de revisão on-line, ou seja, a revisão realizada no decorrer da

\footnotetext{
${ }^{2}$ Nossa tradução para: "is the time delay between the appearance of the source texto on the screen and the typing of the first text production key."

${ }^{3}$ Nossa tradução para: "runs from the first text production keystroke until the first typing of the final punctuation mark."

${ }^{4}$ Nossa tradução para: "[c]hanges are made, typing erros are corrected, existing text is deleted and replaced by new text (...)."
} 
execução da tarefa, que se diferencia da fase de revisão propriamente dita, a terceira fase.

Na fase de revisão, "o texto produzido na fase de redação é revisado (...), a produção textual é consideravelmente menor (...), pois a atividade principal consiste em monitorar o texto produzido" 5 (JAKOBSEN, 2002, p. 193). As mudanças realizadas no texto-alvo nessa fase incluem, por exemplo, correções de pontuação, de erros de gramática e ortografia “(...) até o tradutor decidir que a sua tradução está pronta para ser enviada como concluída" ${ }^{6}$ (JAKOBSEN, 2002, p. 193).

Visando analisar a distribuição do tempo total de execução de tarefas de tradução nas fases do processo tradutório, Jakobsen (2002) desenvolve um estudo em que quatro estudantes de tradução e quatro tradutores profissionais executaram duas tarefas de tradução L2=>L1 e duas tarefas de tradução L1=>L2 no par linguístico dinamarquês (L1) $\Leftrightarrow$ inglês (L2), sendo uma das tarefas realizada com TAP e outra sem TAP em cada direção (L1=>L2 e L2=>L1). Em Jakobsen (2002), assim como em Jakobsen (2003), para a execução da tarefa de tradução L1=>L2 sem TAP, os tradutores profissionais traduziram o texto 1, com 367 caracteres, e os estudantes de tradução o texto 2, com 522 caracteres, havendo, portanto, uma diferença de 155 caracteres entre os dois textos, ou seja, o texto 2 era $42,23 \%$ mais extenso que o texto 1 .

Segundo Jakobsen (2002), para executarem essa tarefa de tradução, os tradutores profissionais levaram em média 7,88 segundos na fase de orientação do texto 1, enquanto os estudantes despenderam em média 19,96 segundos nessa fase do texto 2. Sendo assim, houve uma diferença de 12,08 segundos entre os resultados dos dois grupos, o que corresponde a um aumento de 153,30\% no tempo despendido pelos estudantes nessa fase. Na fase de redação, a diferença de distribuição do tempo

\footnotetext{
${ }^{5}$ Nossa tradução para: "the text that was drafted in the midle phase is reviewed (...), text production speed is considerably lower (...), because the main activity is monitoring of existing text."

${ }^{6}$ Nossa tradução para: “(...) until the translator decides that a translation is ready to be submitted as finished."
} 
percentual entre os tradutores profissionais e os estudantes foi de 109,74\%, uma vez que, em média, os tradutores profissionais despenderam 390 segundos e os estudantes 818 segundos para completar essa fase. Desse modo, apesar de a diferença de extensão dos textos-fonte ser de cerca de $40 \%$, a diferença de distribuição de tempo nas fases de orientação e redação foi superior a 100\%, indicando que mesmo que os textos tivessem uma extensão semelhante, provavelmente os estudantes teriam despendido mais tempo que os tradutores profissionais em cada uma dessas fases.

Embora Jakobsen (2002) não apresente resultados do tempo despendido na fase de revisão separadamente na tradução dos textos 1 e 2 por ambos os grupos, o autor aponta que os tradutores profissionais dedicaram muito mais tempo a essa fase que os estudantes de tradução, mesmo que o texto-alvo produzido pelos tradutores já fosse mais "durável" que o texto-alvo traduzido pelos estudantes ao final da fase de redação. Um texto durável, segundo Alves (2005, p. 120), é um texto que apresenta uma "estrutura coesiva e níveis de coerência textual que o classifiquem como uma produção textual adequada". O desempenho superior dos tradutores profissionais na fase de redação, segundo Jakobsen (2002), se deve ao fato de que:

Assim que uma solução era encontrada e recebia autorização do censor interno do tradutor para ser digitada, ela ficava mais propensa a sobreviver na versão final do texto-alvo que as soluções muito mais instáveis e provisórias redigidas pelos estudantes de tradução. ${ }^{7}$ (JAKOBSEN, 2002, p. 203).

Integrando parte dos aspectos do processo tradutório investigados por Jakobsen (2002; 2003), Buchweitz e Alves (2006) analisaram o tempo total de execução de tarefas de tradução L2=>L1 e L1=>L2 e a distribuição desse tempo nas fases do processo tradutório. Utilizando o programa Translog, os dez participantes do estudo

\footnotetext{
${ }^{7}$ Nossa tradução para: "Once a solution had been found and allowed by the translator's internal censor to be typed, it was more likely to survive into the final target text version that the much more volatile and tentative solutions produced by the student translators".
} 
traduziram um texto jornalístico do inglês para o português (L1) e outro texto do português para o inglês (L2), sendo esses participantes divididos em dois grupos: cinco tradutores com graduação na área de tradução e linguagem e com alguma experiência profissional e cinco estudantes de tradução sem experiência profissional.

Buchweitz e Alves (2006) relatam que, na fase de orientação da tarefa de tradução $\mathrm{L} 1=>\mathrm{L} 2$, os tradutores profissionais despenderam $8 \%$ e os estudantes $4 \%$ do tempo total da tarefa; na fase de redação, os tradutores despenderam $70 \%$ e os estudantes $87 \%$ do tempo total dessa tarefa; e na fase de revisão, os tradutores despenderam $22 \%$ e os estudantes $9 \%$ do tempo total da tarefa, ou seja, os tradutores profissionais despenderam, em média, 4\% mais tempo na fase de orientação, 17\% menos tempo na fase de redação e $13 \%$ mais tempo na fase de revisão que os estudantes. Desse modo, os participantes, independentemente da experiência em tradução, despenderam mais tempo na fase de redação do processo tradutório, corroborando os resultados de Jakobsen (2002). Além disso, Buchweitz e Alves (2006) ressaltam, tal como apontado pelo autor, que os tradutores profissionais atingem um texto durável já na fase da redação.

Assim como Jakobsen (2002, 2003), Pavlović e Jensen (2009) também investigam a direcionalidade em tradução, mas com enfoque na análise de diferentes indicadores de dispêndio de esforço cognitivo por tradutores profissionais e estudantes de tradução em uma tarefa de tradução L2=>L1 e outra de tradução L1=>L2 no par linguístico dinamarquês (L1) >> inglês (L2). Dentre as hipóteses levantadas no estudo, uma delas se apoiava no pressuposto de que, em ambas as direções (L1=>L2 e L2=>L1), haveria maior dispêndio de esforço cognitivo por parte de estudantes de tradução do que por tradutores profissionais em tarefas de tradução semelhantes.

Uma das medidas que Pavlović e Jensen (2009) exploram para confirmar a hipótese de maior dispêndio de esforço cognitivo pelos estudantes de tradução em tarefas de tradução L2=>L1 e L1=>L2 é a duração total de ambas as tarefas realizadas. 
Os resultados dos autores apontam que esse indicador de esforço cognitivo na tarefa de tradução L1=>L2 confirmou a hipótese citada, uma vez que os estudantes despenderam, em média, 17,1\% mais tempo fazendo a tradução L1=>L2 do que os tradutores profissionais.

Baseando-se no estudo de Buchweitz e Alves (2006), Ferreira (2013) investiga aspectos cognitivos do desempenho de oito tradutores profissionais durante a execução de tarefas de tradução L2=>L1 e L1=>L2 de textos de um mesmo domínio e de textos sobre assuntos diferentes no par linguístico inglês (L2)<=>português (L1). Dentre os aspectos investigados pela autora, o tempo total de execução de uma tarefa de tradução L1=>L2 e sua distribuição nas fases do processo tradutório são de especial interesse para o presente estudo.

Os resultados de Ferreira (2013) apontam que o tempo médio total para a execução da tarefa de tradução L1=>L2 pelos participantes foi de 1.392 segundos. Com relação à distribuição desse tempo nas fases do processo tradutório, a autora destaca que o tempo médio despendido na fase de orientação foi de 49,75 segundos, o que correspondeu a uma média de 3,5\% do tempo total de execução da tarefa; na fase de redação, a média de tempo despendido foi de 981 segundos, equivalendo a 70,5\% do tempo total, e a fase de revisão demandou, em média, 362 segundos, ou seja, 26\% do tempo total de execução da tarefa. Dessa forma, o maior dispêndio de tempo ocorre na fase de redação, seguido da fase de revisão e da fase de orientação.

No estudo de Jakobsen e Jensen (2008), dois grupos de participantes (um de tradutores profissionais e um de estudantes de tradução) executaram quatro tarefas distintas envolvendo quatro textos: leitura para compreensão, leitura para posterior tradução, tradução oral e tradução escrita. Nesse estudo, um dos aspectos do processo analisados pelos autores foi o tempo de execução da tarefa. Jakobsen e Jensen (2008) concluem que os tradutores profissionais executaram todas as quatro tarefas em menos tempo que os estudantes. Embora esse estudo não apresente resultados sobre a 
distribuição do tempo total de execução dessa última tarefa entre as fases do processo tradutório, a diferença entre o tempo total despendido pelo grupo de tradutores profissionais (771 segundos) e o tempo demandado pelo grupo de estudantes de tradução (945 segundos) indica que uma característica dos tradutores profissionais é que eles tendem a executar tarefas de tradução mais rapidamente que estudantes de tradução, os quais despenderam 22,5\% mais tempo que os tradutores profissionais.

Quanto à variável velocidade de tradução, Jakobsen (2003) comparou os resultados de estudantes de tradução e tradutores profissionais na execução de tarefas de tradução L1=>L2 e L2=L1 com e sem TAP. Para calcular a velocidade de tradução, o autor levou em consideração o tempo de duração da tarefa em minutos:segundos dividido pelo número de teclas pressionadas durante o processo tradutório. Conforme os resultados do estudo do autor, para a execução da tarefa de tradução L1=>L2 sem TAP, os tradutores profissionais apresentaram uma velocidade média de 75,6 teclas por minuto, enquanto os estudantes de tradução digitaram 57,8 teclas por minuto. Dessa maneira, os tradutores profissionais digitaram uma média de 17,8 mais teclas por minuto que os estudantes.

O’Brien (2007) investiga a velocidade da tradução calculando o número de palavras por minuto do texto-fonte e comparando-a com a velocidade da pós-edição. Como a pós-edição não está no escopo do presente artigo, ressaltam-se neste estudo apenas os resultados de velocidade da tradução relatados por O'Brien (2007). Utilizando o Translog, doze tradutores profissionais participaram do experimento realizado pela autora: nove deles fizeram a pós-edição de um guia de usuário de um software, que havia sido previamente traduzido do inglês para o alemão por um sistema de tradução automática, e três participantes traduziram o mesmo texto-fonte do inglês para o alemão. Os três tradutores profissionais que participaram do estudo da autora traduziram em média 13,63 palavras por minuto do texto-fonte, no par linguístico inglês =>alemão. Tendo em vista que Jakobsen (2003) determinou a 
velocidade de tradução com o número de teclas por minuto, não é possível fazer uma comparação dos resultados do estudo desse autor com os resultados de O’Brien (2007), que se baseou no número de palavras por minuto.

Conforme mencionado anteriormente no início desta seção, o programa Translog pode ser utilizado em conjunto com protocolos verbais para obterem-se mais informações sobre diferentes aspectos do processo tradutório, sob a perspectiva da triangulação. Um desses aspectos é a metarreflexão. Alves (2005, p. 111) argumenta que "níveis mais altos de metarreflexão apontam para uma maior competência em tradução e, portanto, uma maior capacidade de gerenciamento operativo do processo de tradução".

Alves (2005) utiliza a técnica dos protocolos verbais retrospectivos em conjunto com a função Replay do Translog para investigar a metarreflexão, além de outros aspectos do processo tradutório. Cada um dos participantes do estudo do autor realiza a tradução de um texto jornalístico em um par linguístico diferente: alemão => português, espanhol => português e inglês $=>$ português utilizando o Translog. Na sua análise, Alves (2005) relaciona o nível de metarreflexão à durabilidade e à experiência em tradução. Esta pesquisa buscará, conforme indicado na Introdução, relacionar metarreflexão e experiência em tradução. Para investigar essa relação, este estudo analisará protocolos verbais retrospectivos visando a obtenção de evidências de metarreflexão nos relatos dos participantes.

\section{Metodologia}

\subsection{Metodologia de coleta}

Os dados analisados neste estudo foram coletados entre os dias 9 e 10 de novembro de 2010, em um experimento realizado no Laboratório de Computação da Universidade de Macau, em uma parceria com pesquisadores do LETRA da UFMG. Nesse experimento, 17 estudantes do mestrado em Tradução na Universidade de 
Macau, sendo quinze chineses, um brasileiro e um português, realizaram a tradução de um texto-fonte em chinês mandarim para o português europeu sem pressão de tempo e com acesso à Internet para eventuais consultas. O texto-fonte era um texto jornalístico sobre chá verde (cf. Anexo A), que continha um total de 72 palavras e 105 caracteres sem espaço. Uma tradução para leitores que não possuem conhecimento do chinês mandarim é apresentada no Anexo B. ${ }^{8}$

Os 17 participantes do estudo foram divididos em dois grupos de acordo com sua experiência prévia em tradução. Nove deles foram considerados tradutores profissionais e oito deles estudantes de tradução, com base nas informações fornecidas por eles em um questionário, antes do início da coleta, sobre seus perfis acadêmico, linguístico e profissional. Para ser considerado tradutor profissional, o participante deveria possuir pelo menos um ano de experiência profissional e se autodeclarar tradutor profissional. Desse modo, os estudantes de mestrado que atuavam como professores de idioma, tutores e intérpretes também foram incluídos nessa categoria quando atendessem aos critérios mencionados.

Além do questionário, também foram utilizados o Translog e protocolos verbais retrospectivos livres como instrumentos de coleta. Os participantes executaram a tarefa de tradução utilizando o Translog para registrar todos os pressionamentos de teclas, incluindo as teclas de inserção, de exclusão e de navegação, e os movimentos de mouse feitos durante a produção do texto-alvo.

O Translog possui duas interfaces: o Translog User e o Translog Supervisor. No Translog Supervisor, o pesquisador configura o experimento, criando um projeto de tradução e inserindo o texto-fonte em uma das janelas do programa (superior ou inferior) e deixando uma janela para a produção do texto-alvo, se a tarefa a ser executada for uma tarefa de tradução, por exemplo. Atualmente, o programa está na

\footnotetext{
${ }^{8}$ Um texto-alvo em português traduzido por Márcia Schmaltz, que, em comunicação pessoal, sempre advogava em favor de uma tradução do chinês para o português "de forma natural", é apresentado no Anexo B como uma das muitas possíveis traduções para o texto-fonte utilizado nesta pesquisa.
} 
versão Translog II, desenvolvida por Carl (2012), que pode ser integrada a rastreamento ocular, permitindo também analisar dados de leitura, além de outras tarefas de produção textual, como revisão, pós-edição e resumos, que já podiam ser realizadas na versão anterior do programa.

No Translog User, o participante executa a tarefa. Se for uma tarefa de tradução, ele pode visualizar o texto-fonte na janela superior e digitar o texto-alvo na tela inferior. Ao clicar em "Start Logging", o programa começa a registrar o processo de execução da tarefa; ao clicar em "Stop Logging", o programa finaliza o registro do processo.

A função Replay é utilizada no Translog Supervisor para que o pesquisador ou o participante possam assistir à gravação do registro do processo após a execução da tarefa. Além disso, no Translog Supervisor, é possível gerar uma representação linear, que é a transcrição do processo. Essa representação pode ser analisada em conjunto com os protocolos verbais retrospectivos ou concomitantes.

No caso da pesquisa aqui relatada, foram utilizados protocolos verbais retrospectivos livres. Esse tipo de protocolo consiste em solicitar ao participante que ele verbalize livremente sobre o processo da tradução com auxílio da reprodução do processo utilizando a função Replay do programa Translog. Neste estudo, um gravador MP3 portátil foi utilizado para gravar os protocolos retrospectivos, os quais foram posteriormente transcritos para análise.

\subsection{Metodologia de análise}

Para a análise de dados, foi utilizada a triangulação, como proposto por Jakobsen (1999) e Alves (2001, 2003). Segundo Jakobsen (1999), ao analisar os dados coletados de um mesmo fenômeno - no caso, a tradução - utilizando diferentes métodos, aumenta-se a chance de conhecer mais informações sobre esse objeto. Assim, ao combinar a análise de dados quantitativos coletados utilizando o Translog com os 
dados qualitativos dos protocolos verbais retrospectivos livres, os resultados podem ser mais precisos e confiáveis.

Neste estudo, para evitar que a diferença entre a língua materna afetasse os resultados, decidiu-se descartar os participantes cuja L1 não era o chinês, sendo excluídos, portanto, os participantes brasileiro e português da análise apresentada. Sendo assim, a análise concentra-se primeiramente no tempo de execução da tarefa executada por 15 participantes cuja L1 era o chinês, na distribuição desse tempo nas fases de orientação, redação e revisão (JAKOBSEN, 2002), na velocidade de tradução (O'BRIEN, 2007; JAKOBSEN, 2003) e no nível de metarreflexão desses participantes (ALVES, 2005).

Em segundo lugar, são analisadas as transcrições dos protocolos verbais retrospectivos livres desses participantes. Por meio da análise de protocolos verbais, é possível estabelecer a relação entre metarreflexão e experiência em tradução, conforme afirma Alves (2005). Para investigar essa relação, todos os protocolos transcritos dos participantes deste estudo foram lidos e analisados sem identificação dos participantes, a fim de evitar que o conhecimento prévio sobre a experiência em tradução deles interferisse na análise. Somente após a identificação de evidências de metarreflexão nos relatos retrospectivos procedeu-se a verificação a qual dos dois grupos (tradutores profissionais ou estudantes de tradução) os relatos pertenciam.

\section{Resultados}

Os resultados do presente estudo são apresentados e discutidos nesta seção. Eles abrangem o tempo total de execução da tarefa de tradução em tempo absoluto (em segundos) e em tempo relativo (percentual), a distribuição desse tempo nas fases de orientação, redação e revisão (JAKOBSEN, 2002), a velocidade de tradução (JAKOBSEN, 2003) e as evidências de metarreflexão (ALVES, 2005) nos protocolos retrospectivos livres. 


\subsection{Tempo total de execução da tarefa e distribuição de tempo nas fases do processo tradutório}

A Tabela 1 apresenta os tempos absoluto e relativo da execução da tarefa e a distribuição desse tempo nas fases do processo tradutório do grupo de tradutores profissionais. Nas colunas da tabela, é apresentado primeiro o tempo absoluto de cada fase (em segundos), seguido do tempo percentual de cada fase com relação ao tempo total de execução da tarefa apresentado na última coluna em segundos. Na última linha da tabela, é apresentada a média de cada tempo (absoluto e percentual).

Tabela 1 - Tempos absoluto e relativo de realização da tarefa e distribuição desse tempo nas fases do processo tradutório - Tradutores profissionais.

\begin{tabular}{c|c|c|c|c|c|c|c} 
& $\begin{array}{c}\text { Orientação } \\
\mathbf{( s )}\end{array}$ & $\begin{array}{c}\text { Orientação } \\
\mathbf{( \% )}\end{array}$ & $\begin{array}{c}\text { Redação } \\
\mathbf{( s )}\end{array}$ & $\begin{array}{c}\text { Redação } \\
\mathbf{( \% )}\end{array}$ & $\begin{array}{c}\text { Revisão } \\
\mathbf{( s )}\end{array}$ & $\begin{array}{c}\text { Revisão } \\
\text { (\%) }\end{array}$ & $\begin{array}{c}\text { Tempo total } \\
\text { (s) }\end{array}$ \\
\hline P01 & 18 & $2 \%$ & 920 & $98 \%$ & 0 & $0 \%$ & 938 \\
\hline P02 & 31 & $3 \%$ & 958 & $91 \%$ & 61 & $6 \%$ & 1.050 \\
\hline P05 & 06 & $1 \%$ & 697 & $85 \%$ & 114 & $14 \%$ & 817 \\
\hline P06 & 0 & $0 \%$ & 733 & $87 \%$ & 110 & $13 \%$ & 843 \\
\hline P08 & 56 & $3 \%$ & 1.580 & $91 \%$ & 108 & $6 \%$ & 1.744 \\
\hline P11 & 03 & $1 \%$ & 950 & $81 \%$ & 215 & $18 \%$ & 1.168 \\
\hline P15 & 03 & $1 \%$ & 969 & $92 \%$ & 73 & $7 \%$ & 1.045 \\
\hline Média & 17 & $2 \%$ & 972 & $89 \%$ & 97 & $9 \%$ & 1.086
\end{tabular}

Fonte: elaborada pelos autores.

Essa tabela mostra que a média de tempo de execução da tarefa de tradução pelos tradutores profissionais foi de 1.086 segundos. Além disso, observa-se que, dentre os tradutores profissionais, P08 foi o participante que despendeu mais tempo para executar a tarefa (1.744 s) e P06 foi o participante que executou a tarefa em menos tempo (843 s).

Observa-se também que todos os tradutores profissionais dedicaram mais tempo à fase de redação do que às outras fases (orientação e revisão). Os tradutores profissionais despenderam entre $0 \%$ a 3\% do tempo total na fase de orientação, entre $81 \%$ e $98 \%$ do tempo total na fase de redação e entre 0 e $18 \%$ do tempo total na fase de 
revisão, com uma média de $2 \%, 89 \%$ e $9 \%$ do tempo total nas fases de orientação, redação e revisão, respectivamente.

A Tabela 2 a seguir apresenta os resultados dos estudantes de tradução.

Tabela 2 - Tempos absoluto e relativo de realização da tarefa e distribuição desse tempo nas fases do processo tradutório - Estudantes de tradução.

\begin{tabular}{c|c|c|c|c|c|c|c} 
& Orientação (s) & Orientação (\%) & Redação (s) & Redação (\%) & Revisão (s) & Revisão (\%) & Tempo total (s) \\
\hline P03 & 200 & $24 \%$ & 554 & $69 \%$ & 53 & $6 \%$ & 807 \\
\hline P04 & 10 & $2 \%$ & 556 & $94 \%$ & 27 & $4 \%$ & 593 \\
\hline P07 & 02 & $1 \%$ & 1054 & $84 \%$ & 192 & $15 \%$ & 1.248 \\
\hline P09 & 14 & $2 \%$ & 649 & $84 \%$ & 110 & $14 \%$ & 773 \\
\hline P10 & 55 & $4 \%$ & 1329 & $96 \%$ & 0 & $0 \%$ & 1.384 \\
\hline P12 & 374 & $23 \%$ & 920 & $56 \%$ & 336 & $21 \%$ & 1.630 \\
\hline P14 & 30 & $2 \%$ & 1372 & $92 \%$ & 81 & $6 \%$ & 1.483 \\
\hline P16 & 02 & $1 \%$ & 853 & $79 \%$ & 216 & $20 \%$ & 1.071 \\
\hline Média & 86 & $8 \%$ & 912 & $81 \%$ & 127 & $11 \%$ & 1.124
\end{tabular}

Na Tabela 2, constata-se que P12 foi o estudante de tradução que apresentou o maior tempo total de execução da tarefa (1.630 s) e P04 o menor tempo (593 s), com uma média de 1.124 segundos. Nesse caso, observa-se que o tempo despendido por P12 para executar a tarefa de tradução é quase três vezes maior que o tempo despendido por P04.

Em uma comparação com os resultados dos tradutores profissionais apresentados na Tabela 1, observa-se que o tempo total de execução da tarefa dos estudantes $(1.124 \mathrm{~s})$ foi pouco maior que o tempo total despendido pelos tradutores profissionais (1.086 s), ou seja, os estudantes de tradução despenderam, em média, $3,49 \%$ mais tempo que os tradutores profissionais para finalizar a tarefa. Esses resultados corroboram resultados de pesquisas anteriores, como os Jakobsen (2002), Jakobsen e Jensen (2008) e Pavlović e Jensen (2009), que apontaram maior tempo de execução da tarefa por parte dos estudantes de tradução. Jakobsen (2002) relata que os estudantes demoraram $47 \%$ mais tempo que os tradutores para finalizar a tarefa de tradução, enquanto, na pesquisa de Pavlović e Jensen (2009), os estudantes 
despenderam $17,1 \%$ mais tempo que os tradutores profissionais para concluir a tarefa de tradução. Jakobsen e Jensen (2008), por sua vez, relatam que os tradutores profissionais executaram a tarefa, em média, em 771 segundos, enquanto os estudantes executaram-na em 945 segundos, ou seja, os tradutores traduziram a tarefa 18,4\% mais rápido que os estudantes.

Ao verificar a distribuição do tempo total de execução da tarefa dos participantes nas fases do processo tradutório, observa-se que P03 e P12 foram os estudantes que apresentaram maiores valores percentuais, com $24 \%$ e $23 \%$, respectivamente na fase de orientação. No grupo dos tradutores profissionais, P06 não dedicou nenhum tempo a essa fase, enquanto P02 e P08 dedicaram 3\% do tempo total a essa fase. Os resultados de tempo médio percentual despendido na fase de orientação apontaram uma diferença de $6 \%$ entre os dois grupos de participantes, tendo os tradutores profissionais despendido uma média de $2 \%$ nessa fase e os estudantes de tradução uma média de $8 \%$. Esses resultados são diferentes dos relatados por Buchweitz e Alves (2006), que indicaram que os tradutores profissionais e os estudantes de tradução participantes da sua pesquisa dedicaram em média, respectivamente, $8 \%$ e $4 \%$ do tempo total à fase de orientação. Entretanto, os resultados são semelhantes àqueles encontrados por Ferreira (2013) para o grupo de tradutores profissionais ao executarem uma tradução L1=>L2, em que eles despenderam, em média, 3,5\% do tempo total de execução da tarefa na fase de orientação.

Comparando-se os tempos percentuais médios de ambos os grupos de participantes na fase de redação apresentados na Tabela 1 e na Tabela 2, observa-se que os tradutores despenderam uma média de $89 \%$ do tempo total nessa fase e os estudantes uma média de $81 \%$. Esses tempos médios percentuais despendidos na fase de redação por ambos os grupos de participantes desta pesquisa não corroboram os resultados de Buchweitz e Alves (2006) nem os resultados dos tradutores profissionais da pesquisa de Ferreira (2013). Na pesquisa de Buchweitz e Alves (2006), os resultados 
de tempo médio percentual do grupo de tradutores e dos estudantes de tradução indicam que os tradutores profissionais dedicaram, em média, $70 \%$ do tempo total à fase de redação, enquanto os estudantes despenderam em média $87 \%$ do tempo nessa fase. Apesar de o tempo médio percentual de 70,5\% dos tradutores profissionais na fase de redação do estudo de Ferreira (2013) não comprovar os resultados do presente estudo, constata-se que esses resultados são praticamente iguais aos de Buchweitz e Alves (2006).

Na fase de revisão, conforme os resultados apresentados nas Tabelas 1 e 2, constata-se que, em ambos os grupos, há um participante que não dedicou tempo algum para revisar o texto-alvo: o tradutor profissional P01 e o estudante P10. Observa-se ainda que o tempo médio percentual na fase de revisão é de $9 \%$ para os tradutores profissionais e $11 \%$ para os estudantes, com um tempo médio absoluto de 97 segundos do grupo de tradutores profissionais e de 127 segundos do grupo de estudantes. Esses resultados não corroboram os resultados de Jakobsen (2002), que indicou que os tradutores profissionais despenderam mais tempo nessa fase que os estudantes nem os resultados de Buchweitz e Alves (2006), que relataram que tradutores profissionais despenderam mais tempo na fase de revisão (22\%) do que os estudantes (9\%). Os resultados do presente estudo também são diferentes dos achados de Ferreira (2013), em que os tradutores profissionais despenderam, em média, 26\% do tempo total de execução da tarefa na fase de revisão, um percentual médio próximo àquele encontrado por Buchweitz e Alves (2006).

Quando se contrastam os valores da distribuição de tempo em todas as fases do processo tradutório apresentados nas Tabelas 1 e 2, observa-se que todos os participantes deste estudo despenderam mais tempo na fase de redação, tendo dedicado pelo menos $56 \%$ do tempo a essa fase. Esses resultados corroboram resultados de estudos anteriores (JAKOBSEN, 2002; BUCHWEITZ; ALVES, 2006; FERREIRA, 2013), os quais apontam que é na fase de redação que os participantes 
despendem mais tempo do processo tradutório, independentemente da experiência em tradução.

Constata-se, neste estudo, que a distribuição progressiva de tempo médio percentual nas fases foi bem semelhante nos dois grupos deste estudo, sendo de $2 \%$ na fase de orientação, $9 \%$ na fase de revisão e $89 \%$ na fase de redação no grupo de tradutores profissionais, enquanto essa distribuição foi de $8 \%$ na fase de orientação, $11 \%$ na fase de revisão e $81 \%$ na fase de redação no grupo de estudantes. Ao analisar os questionários, é possível afirmar que a maioria dos participantes deste estudo já realiza traduções, embora o grupo dos estudantes ainda não as faça profissionalmente, mas apenas academicamente. Esta experiência acadêmica em tradução pode ser uma das razões que justificam a semelhança dos valores percentuais dos dois grupos cujo processo tradutório é analisado nesta pesquisa.

Embora a distribuição dos valores percentuais médios encontrados por Buchweitz e Alves (2006) nas fases do processo tradutório, conforme já relatado, sejam diferentes dos relatados neste estudo, observa-se uma mesma progressão de tempo nas fases relatadas pelos autores em ambos os grupos de participantes de seu estudo e na pesquisa aqui descrita, havendo, portanto, uma progressão das fases orientação $\Rightarrow$ revisão $\Rightarrow>$ redação. Enquanto Buchweitz e Alves (2006) evidenciam que os tradutores profissionais dedicaram, em média, $8 \%$ do tempo à fase de orientação, 22\% à fase de revisão e 70\% à fase de redação, o grupo dos estudantes despendeu, em média, $4 \%$ do tempo total na fase de orientação, $9 \%$ na fase de revisão e $87 \%$ na fase de redação.

Além disso, comparando-se os dois grupos de participantes, é possível perceber que o grupo dos estudantes de tradução apresentou maior variação individual em todas as fases, principalmente na fase de redação. No grupo dos tradutores profissionais, P08 foi o participante que despendeu mais tempo, com 1.580 segundos na fase de redação e 1.744 segundos de tempo total, uma diferença discrepante dos 
outros participantes do grupo. Esse participante foi o único que despendeu mais de 1.000 segundos na fase de redação, tendo o restante dos tradutores profissionais despendido de 697 a 972 segundos nessa fase, diferentemente do grupo dos estudantes cuja fase de redação variou de 554 a 1.372 s. No grupo dos estudantes, P07, P10 e P12 obtiveram resultados de 1.054, 1.329 e 1.372 segundos respectivamente, enquanto P03, P04 e P09 despenderam, na devida ordem, 554, 556 e 649 segundos nessa mesma fase. Dessa forma, pode-se concluir que os tradutores profissionais tiveram resultados mais semelhantes entre si que os estudantes de tradução.

\subsection{Velocidade de tradução}

Com base em O’Brien (2007), esta pesquisa analisa a velocidade de tradução calculando o número de palavras por minuto do texto-fonte, que continha 72 palavras. O tempo considerado na análise é o tempo de execução da tarefa de tradução em minutos:segundos (JAKOBSEN, 2003).

Tabela 3 - Velocidade de tradução - Tradutores profissionais.

\begin{tabular}{ccc}
\hline & Duração da tarefa em minutos:segundos & Palavras por minuto \\
\hline P01 & $0: 15: 38$ & 4,61 \\
\hline P02 & $0: 17: 30$ & 4,11 \\
\hline P05 & $0: 13: 37$ & 5,29 \\
\hline P06 & $0: 14: 03$ & 5,12 \\
\hline P08 & $0: 29: 04$ & 2,48 \\
\hline P11 & $0: 19: 28$ & 3,70 \\
\hline P15 & $0: 17: 25$ & 4,13 \\
\hline Média & $0: 18: 06$ & 4,21 \\
\hline & Fonte: elaborada pelos autores.
\end{tabular}


Tabela 4 - Velocidade de tradução - Estudantes de tradução.

\begin{tabular}{ccc}
\hline Estudantes & Duração da tarefa em minutos:segundos & Palavras por minuto \\
\hline P03 & $0: 13: 27$ & 5,35 \\
\hline P04 & $0: 09: 53$ & 7,28 \\
\hline P07 & $0: 20: 48$ & 3,46 \\
\hline P09 & $0: 12: 53$ & 5,59 \\
\hline P10 & $0: 23: 04$ & 3,12 \\
\hline P12 & $0: 27: 10$ & 2,65 \\
\hline P14 & $0: 24: 43$ & 2,91 \\
\hline P16 & $0: 17: 51$ & 4,03 \\
\hline Média & $0: 18: 44$ & 4,30 \\
\hline
\end{tabular}

Fonte: Elaborada pelos autores.

Conforme as Tabelas 3 e 4, a maior velocidade de tradução, no grupo dos tradutores profissionais, foi de P05, com 5,29 palavras/minuto. No grupo dos estudantes, P04 apresentou a maior velocidade de tradução, com 7,28 palavras/minuto. Em contrapartida, a menor velocidade de tradução, no grupo dos tradutores profissionais foi de P08, com 2,48 palavras/minuto; no grupo dos estudantes, foi de P12, com 2,65 palavras/minuto.

Dentre os fatores que podem influenciar essa diferença de velocidade de tradução entre os grupos e entre os participantes de cada grupo, acredita-se que um maior dispêndio de tempo na fase de orientação seja o mais relevante. Ao apresentar um menor tempo na fase de orientação, o participante despendeu o restante do tempo de execução da tarefa lendo e compreendendo o texto-fonte e processando o textoalvo, o que resultou em uma diminuição da sua velocidade de tradução. P03, por exemplo, teve uma alta velocidade de tradução (5,35 palavras/minuto) e despendeu 24\% do tempo total na fase de orientação, enquanto P08, P10 e P07, com baixa velocidade de tradução (respectivamente 2,48; 3,12 e 3,46 palavras/minuto), despenderam, respectivamente, 3\%, 4\% e 1\% do tempo total nessa fase.

Embora haja processos tradutórios de participantes em que não é possível perceber essa relação entre maior tempo na fase de orientação e maior velocidade de 
tradução ou vice-versa (P12, por exemplo, com mais tempo na fase de orientação e menor velocidade de tradução, e P04, com menos tempo na fase de orientação e mais velocidade de tradução), pode-se supor que a fase de orientação pode influenciar a velocidade de tradução, uma vez que, em geral, há uma tendência de maior dispêndio de tempo nessa fase de orientação e maior velocidade de tradução.

Ao considerarem-se os resultados apresentados nas Tabelas 3 e 4, observa-se que os estudantes traduzem mais rapidamente que os tradutores profissionais, com uma média de 4,30 palavras/minuto enquanto os tradutores profissionais traduzem em média 4,21 palavras/minuto. Esses resultados não corroboram os resultados de Jakobsen (2003), que, ao calcular a velocidade de tradução, constatou que os tradutores profissionais foram mais rápidos que os estudantes.

Embora O’Brien (2007) não tenha comparado a velocidade de tradução de tradutores profissionais com a de estudantes, os tradutores profissionais da pesquisa da autora traduziram, em média, 13,63 palavras/minuto, enquanto, neste estudo, a média da velocidade de tradução foi de 4,21 palavras a cada minuto. Pressupõe-se que essa diferença de resultados dos tradutores profissionais entre o presente estudo e o da autora possa ser devido à proximidade entre a língua-fonte (alemão) e a línguaalvo (inglês), par linguístico em que o experimento da autora foi realizado, e a distância entre a língua-fonte (chinês mandarim) e a língua-alvo (português europeu), par linguístico do presente estudo. Desse modo, acredita-se que o fato de o tradutor precisar reestruturar as frases na hora de traduzir (já que, por exemplo, o mandarim é uma língua Sujeito - Objeto - Verbo, diferentemente do português) demande mais tempo, causando essa variação de número de palavras por minuto.

\subsection{Evidências de metarreflexão}

Os protocolos retrospectivos livres fornecem principalmente informações qualitativas sobre o processo tradutório, como, por exemplo, as dificuldades 
encontradas pelos participantes durante o processo tradutório e as estratégias mais utilizadas por eles para resolver esses problemas. Na pesquisa aqui relatada, as transcrições dos protocolos foram analisadas para investigar o nível de metarreflexão dos participantes, considerando-se a capacidade de detalhar as escolhas tradutórias durante o processo, o monitoramento e a preocupação com a estratégia de tradução adotada (literal, criativa, etc.). Com relação a esse último aspecto, Alves (2005, p. 146) afirma que "independentemente do nível de experiência, os relatos retrospectivos revelam como este é um ponto de orientação para a meta-reflexão dos sujeitos".

Nas transcrições dos protocolos retrospectivos livres dos participantes, foi possível identificar evidências de metarreflexão. Ressalta-se novamente que, com base em Alves (2005), acreditava-se que participantes do grupo de tradutores profissionais apresentariam maior nível de metarreflexão e que os protocolos transcritos foram analisados sem fazer distinção entre aqueles participantes que eram tradutores profissionais e aqueles que eram estudantes de tradução. Esses participantes só foram identificados como pertencentes a um desses grupos após serem identificados os participantes que possuíam evidências de metarreflexão em seus relatos. As análises apresentadas a seguir correspondem aos relatos de alguns participantes que apresentaram evidências de metarreflexão.

P02, por exemplo, atua profissionalmente como tradutor na área jurídica e dedica em torno de oito horas diárias à tradução. Ele detalha o processo tradutório, explicitando pensamentos e dificuldades que enfrenta durante a execução da tarefa tradutória. Esse participante monitora constantemente o processo tradutório, pois, enquanto traduz, pensa em outras soluções e as avalia como adequadas ou não. Um exemplo é o trecho do relato desse participante: "depois, encontrei no website a palavra 'substâncias', acho que esta é melhor que a tradução original 'elemento', por isso parei e a substitui por 'substância'", em que o participante relata que interrompe 
o processo tradutório para consultar um apoio externo (um site na Web) e depois altera a opção tradutória feita inicialmente.

P11 é tradutor e professor e realiza traduções ao menos uma vez por dia. Ele descreve detalhadamente o processo tradutório, reflete sobre ele e o monitora durante a realização da tarefa. Isso pode ser constatado no trecho em que P11 afirma que “depois de traduzir aquele 'prazo de validade', estive a pensar a melhor forma de dizer: 'cheiro peculiar' ou 'sabor peculiar'".

Outro participante que demonstrou algum nível de metarreflexão é P15, que afirma realizar traduções remuneradas ocasionalmente, traduzindo majoritariamente para si mesmo e para amigos. Ele reflete sobre a escolha das formas verbais, revisandoas e substituindo-as até ter certeza de que a forma escolhida é a adequada, demonstrando assim um monitoramento do processo tradutório. Os dois trechos a seguir do relato desse participante demonstram esse monitoramento: "Parei aqui porque eu pensei se podia usar a voz passiva ativa, decidi adaptar por uma forma voz passiva, e continuando, e aqui tem uma pausa temporal, estive a pensar qual é a forma mais adequada." e "Nesta pausa, voltando várias vezes às partes anteriores, porque estava a pensar se eu devia pôr em forma nominal ou em forma verbal".

P09 não realiza traduções profissionais, portanto encontra-se no grupo de estudantes de tradução, ou seja, está no grupo dos participantes que se acreditava ter menor nível de metarreflexão. Apesar disso, ele é o participante que detalha mais o seu processo tradutório, verbalizando as dificuldades que apresentou e os pensamentos que teve durante a realização da tarefa tradutória e monitorando o seu desempenho no processo. P09 também comenta sobre o aspecto mencionado por Alves (2005), a tradução literal: “depois de digitar a palavra 'beber', tinha pensado que se colocar 'beber' aqui, a tradução é pouco transliteral".

Dentre os participantes citados, P02, P11 e P15 fazem parte do grupo de tradutores profissionais, e P09 é do grupo de estudantes de tradução. Assim, 42\% dos 
tradutores profissionais e 12\% dos estudantes apresentaram evidências de metarreflexão. Portanto, há uma indicação de que os tradutores profissionais têm maior capacidade de gerenciamento operativo do processo de tradução, ou seja, maior nível de metarreflexão, que os estudantes de tradução. Além disso, é possível observar que, dentre os tradutores profissionais, a maioria afirmou realizar traduções diariamente, o que pode indicar que a frequência de realização de traduções, para além de anos de experiência, seja também um fator a ser considerado no aumento do nível de metarreflexão.

Conforme já relatado, Jakobsen (2002) afirma que os estudantes tendem a realizar diversas alterações provisórias no texto-alvo. Ao analisar os relatos, foi possível constatar que os estudantes, em sua maioria, declararam mais frequentemente terem realizado mudanças provisórias que os tradutores profissionais, entretanto esses estudantes não refletem ou refletem pouco sobre elas, conforme se espera de participantes com menor nível de metarreflexão.

\section{Considerações finais}

O presente estudo visou contribuir para os estudos processuais da tradução analisando o processo tradutório de estudantes de tradução e de tradutores profissionais no par linguístico chinês mandarim $\Rightarrow$ português europeu. Para essa investigação, este estudo partiu das hipóteses de que os tradutores profissionais (1) executam tarefas de tradução mais rapidamente que os estudantes de tradução (JAKOBSEN, 2002; JAKOBSEN; JENSEN, 2008); (2) despendem maior tempo na fase de revisão que os estudantes de tradução (JAKOBSEN, 2002, BUCHWEITZ; ALVES, 2006), (3) apresentam maior velocidade de tradução do que os estudantes de tradução (JAKOBSEN, 2003), e (4) possuem maior nível de metarreflexão do que os estudantes de tradução (ALVES, 2005). Algumas dessas hipóteses foram confirmadas conforme as conclusões a seguir. 
Os resultados indicaram que os tradutores profissionais apresentaram um tempo total de execução da tarefa de tradução menor que o tempo de execução dos estudantes. Enquanto os tradutores profissionais despenderam, em média, 1.086 segundos para finalizar a tarefa, os estudantes uma média de 1.124 segundos, ou seja, eles finalizaram a tarefa em $3,49 \%$ mais tempo que os tradutores. Desse modo, foi possível confirmar a primeira hipótese, embora não tenham sido realizados testes estatísticos dada a pequena amostra de participantes.

Os resultados apontaram que os estudantes despenderam, em média, 11\% do tempo total de execução da tarefa nessa fase, enquanto os tradutores profissionais dedicaram 9\% desse tempo. Os estudantes de tradução, portanto, apresentaram maior média percentual de tempo na fase de revisão que os tradutores profissionais, com uma diferença de $2 \%$. Dessa maneira, esses resultados não confirmam a hipótese de que os tradutores profissionais dedicam mais tempo à fase de revisão que os estudantes de tradução. Essas diferenças, contudo, não são relevantes do ponto de vista quantitativo.

Esperava-se que a média da velocidade de tradução dos tradutores profissionais fosse maior que a média da velocidade de tradução dos estudantes de tradução. Essa hipótese não foi confirmada porque os resultados mostraram que os estudantes apresentaram uma maior média de velocidade de tradução; os tradutores profissionais traduziram, em média, 4,21 palavras/minuto e os estudantes 4,30 palavras/ minuto. Ressalta-se, entretanto, que a diferença entre esses dois resultados não é relevante do ponto de vista quantitativo.

Como $42 \%$ dos tradutores profissionais apresentou evidências de metarreflexão, em contraposição a 12\% dos estudantes, há uma indicação de que os relatos dos tradutores profissionais apresentam evidências que apontam maior nível de metarreflexão que os estudantes de tradução. Entretanto, é necessário desenvolver, para estudos futuros, um método para melhor classificar o nível de metarreflexão dos 
participantes em níveis altos ou baixos, em um continuum, levando-se em consideração o conteúdo dos relatos, a experiência em tradução e a frequência de execução de traduções.

É importante salientar que, mesmo nos casos em que as hipóteses deste estudo foram confirmadas, as diferenças entre os resultados dos tradutores profissionais e estudantes de tradução são mínimas. Essas diferenças podem estar relacionadas ao fato de todos os participantes desta pesquisa serem estudantes de mestrado e realizarem traduções com frequência. Dessa forma, o perfil de ambos os grupos é bem semelhante, exceto pela experiência dos tradutores que realizam traduções profissionalmente há pelo menos um ano e com bastante frequência.

Ressalta-se que este trabalho visou contribuir para a pesquisa processual em tradução realizando um estudo no par linguístico chinês mandarim $=>$ português europeu, visto que há poucas pesquisas que envolvem este par em questão. Além disso, este estudo apresentou resultados referentes ao processo tradutório tanto de tradutores profissionais quanto de estudantes de tradução, possibilitando apontar a influência da experiência em tradução em comparação com outros estudos. Embora os resultados do presente estudo não corroborem muitos dos resultados de estudos anteriores devido ao tamanho da amostra e à semelhança de perfil dos participantes, eles podem apontar para novas pressuposições em pesquisas futuras que envolvam o Chinês mandarim como língua-fonte e outras línguas-alvo ocidentais, além da língua portuguesa.

Por fim, dado o tamanho da amostra de participantes deste estudo, conforme já mencionado, não foi possível realizar testes estatísticos que comprovassem a significância dos resultados encontrados. Desse modo, sugere-se a ampliação desse estudo para que sejam feitas outras coletas de dados processuais nesse par linguístico e que sejam feitos testes a fim de confirmar ou refutar estatisticamente esses resultados. Para o desenvolvimento de mais pesquisas com os dados coletados, aponta-se também 
a necessidade de se analisar o ritmo cognitivo e a segmentação dos dados processuais coletados com base em Alves (2005). Além disso, recomenda-se também investigar a revisão online, partindo do estudo de Jakobsen (2002). Acredita-se que esses estudos se complementam, podendo-se, a partir de diferentes aspectos do processo tradutório, investigar mais indícios do papel da experiência em tradução.

\section{Agradecimentos}

Os autores agradecem à profa. Dra. Adriana Silvina Pagano, professora titular da Universidade Federal de Minas Gerais, pela contribuição efetiva na produção deste artigo.

\section{Referências bibliográficas}

ALVES. F. Ritmo cognitivo, Meta-reflexão e Experiência: parâmetros de análise processual no desempenho de tradutores novatos e experientes. In: PAGANO, A.; MAGALHÃES, C.; ALVES, F. (org.). Competência em Tradução: cognição e discurso. Belo Horizonte: Editora da UFMG, 2005. p. 109-153. DOI https://doi.org/10.1590/s010244502003000300006.

ALVES, F. (ed.). Triangulating translation: perspectives in process-oriented research Benjamins Translation Library 45). Amsterdam: John Benjamins, 2003. DOI https://doi.org/10.1075/btl.45.

ALVES, F. A triangulação como opção metodológica em pesquisas empíricoexperimentais em tradução. In: PAGANO, A. S. (org.). Metodologias de pesquisa em tradução. Série Estudos Lingüísticos, v. 3. Belo Horizonte: FALE-UFMG, 2001. p. 6992. DOI https://doi.org/10.1590/1983-21172014150107.

BUCHWEITZ, A; ALVES. F. Cognitive adaptation in translation: an interface between language direction, time, and recursiveness in target text production. Letras de Hoje, v. 41, p. 241-272, 2006.

CARL, M. Translog-II: a Program for Recording User Activity Data for Empirical Reading and Writing Research. In: LREC 2012. Proceedings of the Eighth International Conference on Language Resources and Evaluation (LREC-2012) 
Istanbul, Turkey: European Language Resources Association (ELRA), p. 4108-4112, 2012.

FERREIRA, A. Direcionalidade em tradução: uma investigação do processamento cognitivo de tradutores profissionais em tradução direta e inversa no par linguístico inglês-português. 2010. 137 f. Dissertação (Mestrado em Estudos Linguísticos) Faculdade de Letras, Universidade Federal de Minas Gerais, Belo Horizonte, 2010. DOI https://doi.org/10.5007/2175-7968.2012v1n29p73.

FERREIRA, A. A. Direcionalidade em tradução: o papel da subcompetência bilíngue em tarefas de tradução L1 e L2. 2013. 177 f. Tese (Doutorado em Estudos Linguísticos) - Faculdade de Letras, Universidade Federal de Minas Gerais, Belo Horizonte, 2013. DOI https://doi.org/10.22355/exaequo.2016.34.09.

GONÇALVES, J. L. V. R. Pesquisas empírico-experimentais em tradução: os protocolos verbais. In: PAGANO, A. (org.). Metodologias de pesquisa em tradução. Belo Horizonte: Editora UFMG, 2001, p. 13-41. DOI https://doi.org/10.5007/21757968.2014v1n33p343.

HURTADO ALBIR, A.; ALVES, F. Translation as a cognitive activity. In: MUNDAY, J. (Ed.). The Routledge Companion to Translation Studies. London: Routledge, 2009. p. 54-73.

JAKOBSEN, A. L. Effects of think aloud on translation speed, revision, and segmentation. In: ALVES, F. (ed.). Triangulating translation: perspectives in processoriented research. Amsterdam: John Benjamins Publishing Company, p. 69-95, 2003. (Benjamins Translation Library, n. 45). DOI https://doi.org/10.1075/btl.45.08jak.

JAKOBSEN, A. L. Translation drafting by professional translators and by translation students. In: HANSEN, G. (ed.) Empirical translation studies: process and product. Copenhagen: Samfundslitteratur, 2002, p. 191-204.

JAKOBSEN, A. L. Logging target text production with Translog. In: HANSEN, G. (ed.). Probing the process in translation: methods and results. Frederiksberg: Samfundslitteratur, 1999, p. 9-20. (Copenhagen Studies in Language, n. 24).

JAKOBSEN, A. L.; JENSEN, K. T. H. Eye movement behavior across four different types of reading task. Copenhagen Studies in Language, n. 36, p. 103-124, 2008.

O'BRIEN, S. An empirical investigation of temporal and technical post-editing effort. Trans Interpret Stud (tis) II(I), p. 83-136, 2007. 


\section{Anexo A - Texto-fonte}

茶葉

茶葉採摘後與空氣中的氧接觸, 進行酵素氧化作用即醱酵。製茶時茶葉採摘後為避免 醱酵, 而馬上殺菁製成的茶葉就稱為「不醱酵茶」。這種茶葉經沖泡後湯色較為青綠 所以稱為「綠茶」。

Fonte: http://mytenren.com/board.asp?WebID=41\&NID=161

\section{Anexo B - Texto-alvo traduzido por Márcia Schmaltz \\ O chá verde}

Classificado como não fermentado, o chá verde possui a característica de preservar os seus nutrientes, mas em comparação a outros tipos, oxida-se com maior facilidade; por isso possui um prazo de validade mais curto, o que exige um consumo mais rapidamente, senão é preferível guardá-lo em um lugar ao abrigo da luz. Não é aconselhável guardá-lo dentro da geladeira para que não altere o seu sabor original e seus componentes. 